\title{
Application of Adipose Stem Cell Glue in Facial and Breast Plastic
}

\author{
Li Chunlan, Luo Guanchu, Tan Linwang, Zhou Jiao*
}

Department of Plastic Surgery, Yuebei People's Hospital, Shaoguan, China

Email address:

878897460@qq.com (Zhou Jiao)

${ }^{*}$ Corresponding author

\section{To cite this article:}

Li Chunlan, Luo Guanchu, Tan Linwang, Zhou Jiao. Application of Adipose Stem Cell Glue in Facial and Breast Plastic. Clinical Medicine Research. Vol. 9, No. 6, 2020, pp. 132-135. doi: 10.11648/j.cmr.20200906.12

Received: November 23, 2020; Accepted: December 3, 2020; Published: December 11, 2020

\begin{abstract}
Objective: This study was aimed to evaluate the effect of adipose stem cell gel (SVF-gel) in facial and breast plastic surgery. Methods: A retrospective study of 60 young patients who underwent facial and breast fat transplantation from January 2017 to May 2019 in the Plastic Surgery Department of Yuebei People's Hospital (SVF-gel transplantation group 30 cases, traditional Coleman fat transplantation group 30 cases), and analyze the patient's curative effect. Results: 60 patients were about 35 years old (34.66 \pm 8.76 years old in the SVF-gel group, 35.25 \pm 9.01 in the traditional Coleman fat transplantation group). The BMI of the SVF-gel group was $24.36 \pm 4.02$, while that of the traditional Coleman fat transplantation group was 25.01 \pm 4.05 . The follow-up time of 60 patients was about 8 months. The results showed that the fullness and contour of the face and breast of all patients were improved to varying degrees compared with preoperatively. The satisfaction degree of SVF-gel transplantation group was higher than that of traditional Coleman fat transplantation group. Conclusion: SVF-gel has obvious advantages over traditional fat transplantation in volume filling and rejuvenation of the face and breasts.
\end{abstract}

Keywords: Adipose Stem Cell Gel, Cosmetic Plastic Surgery, Facial Rejuvenation, Breast Plastic Surgery

\section{Introduction}

Fat transplantation has the advantages of easy access to materials, good operation, good appearance, no rejection, long-term effectiveness, body shaping and no obvious scars. At present, fat transplantation technology has been widely used in clinical practice, and it has become the most popular in cosmetic surgery $[1,2]$. However, the long-term survival rate of fat after transplantation is unstable, which limits the wide application of fat transplantation. At present, people apply many methods to improve the survival rate of transplanted fat, such as PRP, PRF and CAL-assisted fat transplantation, including cell-assisted lipotransfer (CLA) technology, by increasing the vascular matrix fragments in the transplanted fat stromal vascular fraction (SVF) cell concentration, thereby improving the survival rate of transplanted fat. However, since the isolated SVF cells need to use collagenase in the extraction process, which increases the risk, which limits its application in clinical. Adipocytes in adipose tissue were removed by pure physical methods to prepare adipose stem cell gel (SVF-gel) [3, 4], an injectable gel-like fat concentrate extract rich in SVF cells and extracellular matrix. It has been proved that the long-term survival rate after transplantation is much higher than that of ordinary fat transplantation [5]. From January 2017 to May 2019, the Plastic Surgery Department of Yuebei People's Hospital used SVF-gel to fill the lack of volume in the face and breasts, and initially achieved good clinical results. Now, we retrospectively compare its effect with traditional fat grafting.

\section{Material Method}

\subsection{Clinical Data}

60 patients were collected in this study. There were 30 cases in the SVF-gel transplantation group. Thirty patients in the traditional coleman fat transplantation group. Smokers, those with history of trauma, surgery, or filler injection in the injection area were not included in the study.

\subsection{Surgical Methods}


After the anesthesia took effect, the liposuction area was infiltrated and anesthetized with normal saline containing $0.001 \%$ epinephrine, and the adipose tissue was extracted with a liposuction needle with an inner diameter of $2.5 \mathrm{~mm}$. In the traditional Coleman fat transplantation group, the obtained fat was centrifuged according to the standard Coleman technique, and then the fat layer (Coleman fat) was taken for transplantation. In the SVF-gel transplantation group, Coleman fat was injected repeatedly and then centrifuged. The gel-like substance under the oil layer was the SVF-gel for transplantation. In the breast, granular fat is mainly transplanted under the breast, and a small amount of fat glue can be transplanted in the subcutaneous tissue layer. The same is true on the face. The areas that need to be filled more are filled with granular fat first, and a small amount of fat glue is transplanted under the skin. We used $27 \mathrm{G}$ to inject evenly under the skin on the face and chest. After surgery, the donor site routinely wears a corset and takes antibiotics and non-steroidal anti-inflammatory drugs for 3 days.

\subsection{Effect Evaluation}

We take photos of patients before and after surgery for comparison. When the patient returned 6 months after the operation, the scale was used to evaluate the patient's satisfaction. The scores included very dissatisfied, dissatisfied, neutral, satisfied and very satisfied.

\subsection{Statistical Analysis}

The SPSS software was used for statistical analysis, the $t$ test was used to compare continuous variables, and the Pearson chi-square test was used to compare categorical variables. The difference was statistically significant with $\mathrm{P}<0.05$.

\section{Results}

\subsection{Comparison of Clinical Data}

From January 2017 to May 2019, 60 young patients underwent facial and breast fat transplantation in the Plastic Surgery Department of Yuebei People's Hospital (30 cases in the SVF-gel transplantation group, 30 cases in the traditional Coleman fat transplantation group). There was no significant difference in age composition, BMI, and follow-up time between the two groups $(\mathrm{P}>0.05)$; the injection volume of the SVF-gel transplantation group was also not statistically different from the traditional Coleman fat transplantation group $(\mathrm{P}>0.05)$, Table 1 .

Table 1. Data of two groups of patients.

\begin{tabular}{llllll}
\hline Groups & n & Age (years, $\left.x_{ \pm \mathbf{s}}\right)$ & BMI & Follow-up time & Injection volume $\left(\mathbf{m l},{ }^{x} \pm \mathbf{s}\right)$ \\
\hline SVF-gel group & 30 & $34.66 \pm 8.76$ & $24.36 \pm 2.13$ & $8.35 \pm 2.13$ & $25.58 \pm 5.72$ \\
Coleman group & 30 & $35.25 \pm 9.01$ & $25.01 \pm 4.15$ & $8.02 \pm 1.95$ & $28.39 \pm 6.91$ \\
\hline
\end{tabular}

\subsection{Satisfaction Comparison}

All patients achieved good facial rejuvenation effect. They manifested as full and natural frontal and temporal regions, disappeared tear grooves, plump apple muscles, disappeared cheeks, straightened noses, nasolabial folds and marionette lines became shallow or disappeared, lips were plump and rosy, and chin protruding. The skin is full and ruddy, the chin is prominent, the skin is white and firm, and the contour is natural. The overall face has a harmonious and natural rejuvenation effect (Figure 1), which is more consistent with previous reports [3]. The chests of the two groups of patients were straight and well-shaped after the operation, and the patients were satisfied (Figure 2). The traditional Coleman fat transplantation group showed obvious absorption within 3 months after the operation, while the SVF-gel transplantation group maintained a satisfactory effect 6 to 13 months after the operation (Figures 1 and 2). The satisfaction degree of the SVF-gel transplantation group was higher than that of the traditional Coleman fat transplantation group $(\mathrm{P}<0.05)$, see Table 2. All the patients had successful operations without serious complications. However, patients in the traditional Coleman fat transplantation group experienced skin surface swelling and subcutaneous hemorrhage after the operation, while the SVF-gel transplantation group did not experience subcutaneous hemorrhage, and the swelling of the skin surface was light and the recovery time was quick.

Table 2. Satisfaction of the two groups of patients.

\begin{tabular}{|c|c|c|c|c|c|c|}
\hline Groups & $\mathbf{n}$ & Very satisfied & Satisfied & General & Dissatisfied & Very dissatisfied \\
\hline SVF- gel group & 30 & 12 & 15 & 3 & 0 & 0 \\
\hline Coleman group & 30 & 5 & 15 & 8 & 2 & 0 \\
\hline
\end{tabular}

\section{Discussion}

This study retrospectively evaluated the application of SVF-gel in facial and breast volume filling and skin rejuvenation. SVF-gel can obtain long-term stable filling effect after facial and breast filling. Although the contour and fullness of the face and breasts of all patients were improved, the SVF-gel group recovered faster after the operation and the patients were more satisfied.

In fat transplantation, SVF helps to enhance the survival rate of transplanted fat. Some scholars first proposed CAL in 2008 [5]. Increasing the percentage of SVF cells in fat grafts can improve the survival rate of fat grafts [6]. Because it is not easy to obtain ADSCs from the donor site during liposuction, the additional ADSCs obtained are diffused into 
the liposuction liquid, resulting in a very small amount of ADSCs in the adipose tissue obtained, resulting in a decrease in the survival rate of fat particle transplantation [7]. Therefore, adding enough ADSCs to the transplanted fat can significantly reduce the incidence of fat transplantation and increase the survival rate of fat $[7,8]$.

SVF-gel enriches ADSCs by purely physical means, which is safe [9]. The cells used in CAL technology include SVF and ADSCs [10]. SVF is obtained by extracting primary cells and its composition is more complex [11]. Among them, ADSCs (CD31-, CD34+, CD45-) account for 37\%, other nucleated cells (CD45+) account for 37\%, and endothelial cells (CD31+, CD34-, CD45-) accounted for 15\%, other cells (CD31-, CD34-, CD45-) accounted for 11\% [12]. However, ADSCs need to be cultured and amplified in vitro. It has the characteristics of high purity and stable performance, but its safety and stability need to be further determined. Because SVF-gel contains large number of ADSCs, and ADSCs can secrete a variety of pro-angiogenic factors and adipogenic factors, all SVF-gel is conducive to fat survival and adipogenic differentiation [13].

Since the transplanted adipose tissue is prone to hypoxia, mature fat cells have the characteristics of high oxygen consumption [14]. Therefore, most mature fats are prone to necrosis after fat transplantation, leading to inflammation, which causes more obvious local edema after fat transplantation. According to the different extraction methods of SVF, CAL is divided into three methods: solid phase CAL method, liquid phase CAL method and full term CAL method [15]. In this study, the solid phase method was used to extract SVF-gel to remove the oil in the fat, so that only mild or no inflammation occurs at the transplant site. Due to the lower survival rate of traditional fat transplantation, in order to achieve the same effect, traditional fat transplantation often needs to be overfilled, so it is easy to cause swelling of the surgical site [16]. In addition, SVF-gel is a jelly-like liquid that can be injected with a $27 \mathrm{G}$ needle, so local tissue damage is less, and local adverse reactions are less.


Figure 1. A 40-year-old woman with $15 \mathrm{ml}$ of SVF-gel (temporal $8 \mathrm{ml} / \mathrm{side}$, chin $7 \mathrm{ml}$ ) filled with $15 \mathrm{ml}$ of SVF-gel on the face. (A) Before surgery; (B, C, and D) 1 week after surgery; (E) 1 month after surgery; $(F)$ Half a year after surgery.
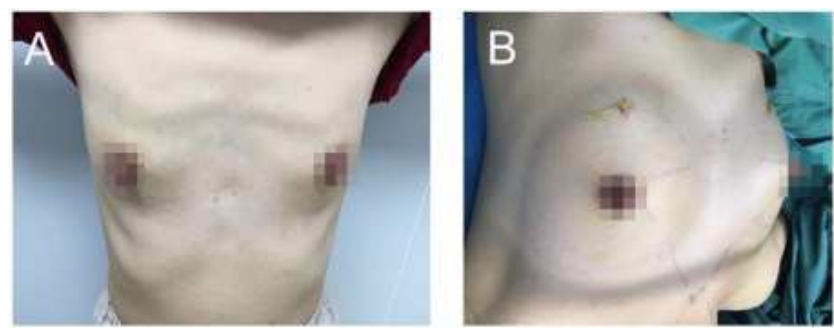

Figure 2. A 45-year-old woman with breast filling. (A) Before surgery; (B) Immediately after surgery.

\section{Conclusion}

SVF-gel has obvious advantages over traditional fat transplantation in the volume filling and rejuvenation of the face and breasts. This treatment significantly reduces the incidence of fat transplantation and increases the survival rate of fat, which is beneficial to reduce the adverse reactions after fat transplantation. To obtain satisfactory curative effect, this method is worthy of extensive clinical application. However, the yield of SVF-gel is low and should be mainly used for the treatment of key parts.

\section{References}

[1] Strong AL, Cederna PS, Rubin JP, Coleman SR, Levi B: The Current State of Fat Grafting: A Review of Harvesting, Processing, and Injection Techniques. Plast Reconstr Surg 2015, 136 (4): 897-912.

[2] Coleman SR, Katzel EB: Fat Grafting for Facial Filling and Regeneration. Clin Plast Surg 2015, 42 (3): 289-300, vii.

[3] Lambros V: Discussion. Improvement of skin quality after fat grafting: clinical observation and an animal study. Plast Reconstr Surg 2009, 124 (3): 775-776.

[4] Mojallal A, Lequeux C, Shipkov C, Breton P, Foyatier JL, Braye F, Damour O: Improvement of skin quality after fat grafting: clinical observation and an animal study. Plast Reconstr Surg 2009, 124 (3): 765-774.

[5] Yoshimura K, Sato K, Aoi N, Kurita M, Inoue K, Suga H, Eto $\mathrm{H}$, Kato H, Hirohi T, Harii K: Cell-assisted lipotransfer for facial lipoatrophy: Efficacy of clinical use of adipose-derived stem cells. Dermatol Surg 2008, 34 (9): 1178-1185.

[6] Yin Y, Li J, Li Q, Zhang A, Jin P: Autologous fat graft assisted by stromal vascular fraction improves facial skin quality: A randomized controlled trial. J Plast Reconstr Aesthet Surg 2020, 73 (6): 1166-1173.

[7] Moustaki M, Papadopoulos O, Verikokos C, Karypidis D, Masud D, Kostakis A, Papastefanaki F, Roubelakis MG, Perrea D: Application of adipose-derived stromal cells in fat grafting: Basic science and literature review. Exp Ther Med 2017, 14 (3): 2415-2423.

[8] Zhang Y, Xiao LL, Li JX, Liu HW, Li SH, Wu YY, Liao X, Rao CQ: Improved fat transplantation survival by using the conditioned medium of vascular endothelial growth factor transfected human adipose-derived stem cells. Kaohsiung J Med Sci 2017, 33 (8): 379-384. 
[9] Cai Y, Li J, Jia C, He Y, Deng C: Therapeutic applications of adipose cell-free derivatives: a review. Stem Cell Res Ther 2020, 11 (1): 312.

[10] Kilinc MO, Santidrian A, Minev I, Toth R, Draganov D, Nguyen D, Lander E, Berman M, Minev B, Szalay AA: The ratio of ADSCs to HSC-progenitors in adipose tissue derived SVF may provide the key to predict the outcome of stem-cell therapy. Clin Transl Med 2018, 7.

[11] Kilroy G, Dietrich M, Wu X, Gimble JM, Floyd ZE: Isolation of Murine Adipose-Derived Stromal/Stem Cells for Adipogenic Differentiation or Flow Cytometry-Based Analysis. Methods Mol Biol 2018, 1773: 137-146.

[12] Suga H, Matsumoto D, Inoue K, Shigeura T, Eto H, Aoi N, Kato H, Abe H, Yoshimura K: Numerical measurement of viable and nonviable adipocytes and other cellular components in aspirated fat tissue. Plast Reconstr Surg 2008, 122 (1): 103-114.
[13] Zhang Y, Cai J, Zhou T, Yao Y, Dong Z, Lu F: Improved Long-Term Volume Retention of Stromal Vascular Fraction Gel Grafting with Enhanced Angiogenesis and Adipogenesis. Plast Reconstr Surg 2018, 141 (5): 676e-686e.

[14] Lempesis IG, van Meijel RLJ, Manolopoulos KN, Goossens GH: Oxygenation of adipose tissue: A human perspective. Acta Physiol (Oxf) 2020, 228 (1): e13298.

[15] Yoshimura K, Sato K, Aoi N, Kurita M, Hirohi T, Harii K: Cell-assisted lipotransfer for cosmetic breast augmentation: supportive use of adipose-derived stem/stromal cells. Aesthetic Plast Surg 2008, 32 (1): 48-55; discussion 56-47.

[16] Rosing JH, Wong G, Wong MS, Sahar D, Stevenson TR, Pu LL: Autologous fat grafting for primary breast augmentation: a systematic review. Aesthetic Plast Surg 2011, 35 (5): 882-890. 